\title{
PENENTUAN MOMEN INERSIA BENDA TEGAR DENGAN METODE BANDUL FISIS
}

\author{
Stepanus Sahala $\mathbf{S}$. \\ Prodi Pend. Fisika, Jurusan PMIPA FKIP Untan
}

\begin{abstract}
The aim of this research is the define rigid inert moment with physical pendulum method. This method is applied to experiment of simple oscilation that it can be used as a new method. Data anaisys is done in two ways, or methods. The result of graphyc analysis in the first way method is the value of inert moment that is obtained from line gradient in graph $h T^{2}$ vs $h^{2}$ is : 6,00 $\pm 0,20\left(10^{-4} \mathrm{~m}^{2} \mathrm{~kg}\right) ; 8,00 \pm 0,50\left(10^{-4} \mathrm{~m}^{2}\right.$ $\mathrm{kg}) ; 10,80 \pm 0,30\left(10^{-4} \mathrm{~m}^{2} \mathrm{~kg}\right)$ and 16,40 $\pm 0,80\left(10^{-4} \mathrm{~m}^{2} \mathrm{~kg}\right)$. The second way method, the graphic analisys is found the value of inert moment in the line gradient from this graph $h T^{2}$ vs $x$ is: 8,10 $\pm 0,40$ $\left(10^{-4} \mathrm{~m}^{2} \mathrm{~kg}\right) ; 10,50 \pm 0,40\left(10^{-4} \mathrm{~m}^{2} \mathrm{~kg}\right) ; \quad$ and $16,10 \pm 0,60\left(10^{-4} \mathrm{~m}^{2}\right.$ $\mathrm{kg}$ ). The rigid moment inert with the physical pendulum has result close to the value of rigid inert moment in the literature. The instrument that is made designed can be used to conduct the experiments in physics laboratory.
\end{abstract}

Keys word: Inert moment, simple oscilation, physical pendulum

Momen kelembaman (I) merupakan sifat fisis dari suatu benda yang salah satu gerak melingkar (rotasi). Seperti halnya dengan massa ( $m$ ) sifat lembam dari benda terhadap gerak translasinya, momen kelembaman juga merupakan sifat lembam benda terhadap gerak rotasinya. Setiap benda tegar yang masing-masing titik partikelnya bergerak melingkari suatu acuan tertentu yang berada di luar benda selalu dapat dicirikan dengan momen kelembamanya (Giancoli, 2001: 136).

Masalah dasar dari penelitian ini adalah metode yang sederhana, tetapi cukup baik untuk mengukur besar momen kelembaman suatu benda. Jika kelembaman translasi $(m)$ diukur dengan membandingkan massa benda dengan massa standar (mengunakan neraca atau timbangan dua lengan), momen, kelembaman (I) diukur dengan mengayunkan benda terhadap suatu titik tumpu. Pada prinsipnya, mengayunkan sama dengan merotasikan, walaupun tidak satu putaran penuh. Dengan prinsip ayunan, rumus momen kelembaman dapat diturunkan melalui persamaan gerak yang sederhana. Akan tetapi, keadaan yang sebenarnya dari ayunan tidaklah sederhana rumus persamaan gerak yang dipakai dalam penelitian ini. Ada dua faktor yang diabaikan dalam penelitian ini, walaupun pengaruh kedua faktor ini menyebabkan ralat total yang nampak dalam grafik-grafik dan analisisnya. Agar diperoleh ralat yang kecil, maka percobaan dilakukan dengan 
menggunakan peralatan yang memadai (Sutrisno, 1997: 98).

Gesekan antara titik tumpu ayun dan benda mengakibatkan ayunan semakin lama semakin lemah (teredam). Sehingga persamaan matematis dari gerak benda melibatkan fungsi eksponensial. Pegaruh gesekan ini dapat diabaikan dengan cara menghaluskan (memperlicin) bagian benda yang bersentuhan dengan titik tumpu osilasi (Khanafiyah, 2012). Penyelesaian matematis dari persamaan gerak benda dibuat sederhana dengan melakukan pendekatan matematis $(\sin \phi \approx \phi)$ (Resnick, 1078).

Konsekuensinya, simpangan benda harus sekecil mungkin. Salah satu sistem fisis yang bergerak mengikuti gerak harmonik sederhana adalah bandul fisis (Physical Pendulum), yaitu benda tegar yang digantungkan sehingga dapat berayun dalam bidang vertikal terhadap sumbu yang melalui benda tersebut (Surya, 2012). Bandul dengan massa $m$ diayunkan dengan sumbu putar melalui $O$ jarak pusat berat bandul adalah $\mathrm{h}$. Momen inersia terhadap sumbu rotasi yang melalui pusat massa adalah:

$$
I_{0}=m k_{0}^{2}+m h^{2}
$$

Momen gaya pada bandul sewaktu sudut simpangan dari bandul sebesar $\phi$ adalah $\approx$ mgh $\sin \phi$, untuk sudut $\phi$ yang kecil $\sin \phi \approx \phi$ (Soetarman, 1978), maka:

$$
\tau=-m g \phi
$$

Dengan menyatakan antara persamaan di atas akan diperoleh:
- mgh $\phi=\mathrm{I} \frac{d^{2} \phi}{d t^{2}} \quad$ (jika faktor redaman $=0$ )

Biasanya dalam percobaan faktor redaman tidak dapat dibuang sama sekali, faktor redaman akan memperlambat ayunan benda, sedemikian sehingga persamaan gerak menjadi:

$$
\begin{aligned}
& -\mathrm{b} \frac{d^{2} \phi}{d t}+(-\mathrm{mgh} \phi)=I \frac{d^{2} \phi}{d t^{2}} \\
& \mathrm{I} \frac{d^{2} \phi}{d t}+\mathrm{b} \frac{d \phi}{d t}-m g h \phi=0
\end{aligned}
$$

Penyelesaian dari Persamaan tersebut adalah :

$\phi=A e^{-B t} \cos \omega t$

Persamaan (2) ini dideferensialkan sekali dan dua kali terhadap $\mathrm{t}$ diperoleh:

$\frac{d \phi}{d t}=-B A \quad e^{-B t} \operatorname{coc} \omega t-\quad(-\omega \mathrm{A})$

$e^{-B t} \sin \omega t$

dan,

$\frac{d^{2} \phi}{d t^{2}}=B^{2} A e^{-B t} \cos \omega t+2 B \omega A e^{-B t} \sin \omega t-$ $\omega^{2} A e^{-B t} \cos \omega t$

sehingga Persamaan (1) menjadi:

$$
\begin{aligned}
& {\left[I\left(B^{2}-\omega^{2}\right)-B b+k\right] \cos } \\
& \omega t+[2 I B \omega+b \omega] \sin \omega t=0
\end{aligned}
$$

Tujuan penelitian ini adalah menentukan nilai momen inersia benda tegar dengan metode bandul fisis. Diharapkan hasilnya dapat memberikan andil dalam pengembangan peralatan laboratorium fisika.

\section{Metode}

1. Peralatan

Alat ukur yang digunakan untuk menentukan besaran-besaran fisis dalam percobaan momen 
kelembaman terdiri atas stopwatch (ketelitian: 0,002 sekon). Jangka sorong (ketelitian: 0,05 $\mathrm{mm}$ ); mistar (ketelitian: 0,5 mm); neraca duduk (ketelitian: 0,05 gram) (Armitage, 1982).

Obyek yang diteliti dalam percobaan ini adalah sebuah bandul fisis (berupa lempengan aluminium yang dilubangi sebanyak dua puluh lubang). Kedua ujung lempengan dipatri dengan dua batang kuningan untuk keperluan pemasangan beban bervariasi.

\section{Percobaan}

Keselarasan antara metode analisa percobaan dan teori terletak pada kepatuhan dalam menentukan sudut awal simpang bandul $(\phi)$, dan pengabaian faktor redaman (Sarojo, 1978). Kepatuhan ini akan menyebabkan timbulnya ralat pada hasil percobaan terhadap teori. Akan tetapi ralat yang dihasilkan oleh adanya kepatuhan ini sangat kecil sehingga bisa diabaikan.

Dalam percobaan ayunan bandul fisis simpangan berkisar pada harga $2^{0}$. Hal ini akan menyumbangkan ralat terhadap teori sebesar:

$$
\frac{\frac{2}{360} \times 2 \pi-\sin 2}{\sin 2} \times 100 \%=0,02 \%
$$

Sumbangan ralat $0,02 \%$ sangat kecil sehingga dalam perhitungan diabaikan.

Faktor kedua adalah terletak pada kepatuhan menentukan faktor redaman. Besar ralat akibat pengaruh faktor redaman terhadap nilai momen kelembaman secara teoritis dapat diperkirakan sebagai berikut ini.
Pada percobaan, periode ayunan berkisar pada nilai satu detik. Dalam 10 kali ayunan, simpangan berkurang sekitar 10\%, sehingga harga $b$ dapat diperkirakan sebagai berikut:

$$
\frac{e(l=10 \operatorname{det} i k)}{e(l=10 \operatorname{det} i k)}=0,9
$$

Atau,

$$
0,9=e^{-\frac{10 b}{2 l}}
$$

dalam perhitungan didapatkan:

$$
b=0,02 l
$$

faktor redaman $\mathrm{b}=0,02 \quad l$ menyumbangkan ralat pada pengukuran periode ayunan $T$ sebesar $\Delta T . \Delta T$ dapat dicari dengan cara sebagai berikut ini. Didenifisikan periode ayunan secara teoritis sebagai $T_{t}$ dan periode ayunan terukur dalam percobaan sebagai $T_{p}$ yang masingmasing dirumuskan:

$T_{t}=2 \pi\left(\frac{m g h}{l}-\left(\frac{b}{2 l}\right)^{2}\right)^{-1 / 2} \mathrm{dan}$

$T_{p}=2 \pi\left(\frac{l}{m g h}\right)^{1 / 2}$

Dalam perhitungan selanjutnya diperoleh:

$$
\begin{aligned}
& \frac{1}{T_{p}}-\frac{1}{T_{t}}=\frac{b^{2}}{16 \pi^{2} l^{2}} \\
& \frac{T^{2} t-T^{2} p}{T p^{2} T t^{2}}=\frac{b^{2}}{16 \pi^{2} l^{2}}
\end{aligned}
$$

dengan menuliskan $T_{t}^{2}-T_{P}^{2}=$ $\Delta(T)^{2}$ dan $T_{t}^{2} T_{P}{ }^{2} \approx T^{4}$ dari perambatan ralat, rumus di atas dapat ditulis sebagai:

$$
\frac{2 T \Delta T}{T^{4}}=\frac{b^{2}}{16 \pi^{2} l^{2}}
$$$$
\text { atau }
$$ 


$$
\Delta T=\frac{b^{2}}{16 \pi^{2} l^{2}} T^{3}
$$

Dari percobaan yang telah dilakukan, besar $T$ berkisar pada satu detik. Ralat teoritis bagi $T=1$ detik dengan $b=0,02 l$ adalah:

$$
\frac{\Delta T}{T} \times 100 \%=0,0001 \%
$$

Sumbangan ralat $0,0001 \%$ sangat kecil sehingga dalam perhitungan dapat diabaikan (Soejoto, 1993). Jadi penganggapan bahwa $b=0$ untuk getaran teredam dalam percobaan yang dilakukan sangatlah bijaksana dan dapat dipertanggungjawabkan. Dalam percobaan ini, besaran fisis yang diukur adalah waktu getar bandul fisis $(T)$ sebagai fungsi jarak titik tumpu ayunan dari titik acuan yang telah ditentukan secara sembarang yaitu $x$.

Terdapat dua buah metode analisa dalam penentuan harga $I_{o}$. Kedua buah metode tersebut adalah seperti yang diuraikan berikut ini:

\section{Metode I}

Dasar perhitungan dalam metode ini adalah dengan memperhatikan letak titik pusat massa sistem. Data yang diperoleh dalam percobaan mengukur waktu getar $\mathrm{T}$ sebagai fungsi jarak titik tumpu terhadap titik acuan, yaitu $x$, dibuat grafik $T^{2}$ vs $x$. Selanjutnya $I_{o}$ dapat ditentukan dari grafik $h T^{2}$ vs $h^{2}$, setelah mengetahui besar slope, misal dinotasikan dengan $A$, dan titik potong grafik, yang dinotasikan dengan $B$.

$$
\begin{aligned}
& \mathrm{A}=\frac{4 \pi^{2}}{g} \\
& \mathrm{~B}=\frac{4 \pi^{2} I_{O}}{m g}
\end{aligned}
$$

\section{Metode II}

Dalam metode ini untuk menentukan momen kelembaman $I_{o}$ tidak menentukan dimana letak pusat massa sistem. Bila variabel $h$ diganti dengan $R-x$, maka setelah dilakukan penjabaran lebih lanjut diperoleh persamaan yang berbentuk:

$$
T^{2}=\frac{4 \pi^{2} R}{g}\left\{\frac{I_{0}}{m R^{2}\left(1-\frac{x}{R}\right)}+\left(1-\frac{x}{R}\right)\right\}
$$

Dari persamaan $T^{2}$, kondisi minimum dicapai jika:

$$
\frac{d^{2} T}{d T^{2}}=0
$$

Dengan perhitungan massa diperoleh:

$$
x_{\text {min }}=\left(1-\sqrt{\frac{I_{0}}{m R^{2}}}\right)
$$

$\mathrm{X}_{\min }$ tersebut bila dimasukan ke persamaan $\frac{d^{2} T}{d T^{2}}=0$ maka diperoleh harga $T_{\min }$ dalam bentuk:

$$
\begin{array}{r}
T^{2}{ }_{M I N}=\frac{8 \pi^{2}}{g} \sqrt{\frac{I_{0}}{m}} \text { atau } \\
I_{0}=\frac{g^{2} T^{4}{ }_{\text {min }}}{64 \pi^{4}} m
\end{array}
$$

dengan $T_{\min }$ ditentukan dari grafik $T^{2}$ vs $x, \mathrm{~g}$ dihitung dari persamaan $T_{\text {mim }}^{2}$, m diukur dengan sebuah neraca. Dan bila hargaharga tersebut dimasukkan ke persamaan $I_{o}$ maka diperoleh harga momen lembam sistem 
terhadap sumbu yang melalui pusat massa.

\section{Hasil dan Pembahasan}

1. Menentukan $I_{o}$ Dengan Metode I

Momen kelembaman $I_{o}$ ditentukan dengan persamaan $I_{0}=\frac{g^{2} T^{4}{ }_{\min }}{64 \pi^{4}} m$ dalam bentuk :

$$
I_{0}=\frac{m g B}{4 \pi^{2}}
$$

Massa bandul $m$ diukur langsung dengan neraca, sedang harga $g$ dapat dihitung dengan menggunakan persamaan:

$$
T^{2}=\frac{4 \pi^{2} R}{g}\left\{\frac{I_{0}}{m R^{2}\left(1-\frac{x}{R}\right)}+\left(1-\frac{x}{R}\right)\right\}
$$

, dimana besar gradien $A$ ditentukan dari grafik $h T^{2} v s h^{2}$ dan $B$ ditentukan sebagai titik potong pada sumbu $h T^{2}$.

Ralat $I_{o}$ yaitu $\Delta I_{o}$ dihitung dengan rumus umum perambatan ralat dalam bentuk :

$$
\Delta I_{o}=\sqrt{\left(\frac{\delta \overline{I_{o}}}{\delta m} \Delta m\right)^{2}+\left(\frac{\delta I_{o}}{\delta g} \Delta g\right)^{2}+\left(\frac{\delta I_{o}}{\delta B} \Delta B\right)^{2}}
$$

Rumus ini dipakai karena semua variabel tak bergayut dan semua ralat rambang. Ralat massa $m$ ditentukan besarnya dengan mempertimbangkan skala terkecil dari neraca yang digunakan, dan besarnya $\pm 0,05$. Sedangkan ralat $g$ yaitu $\Delta g$ dihitung dengan rumus perambatan ralat yaitu:

$$
G=\left|\frac{d g}{d A} \Delta A\right|=\left|\frac{4 \pi^{2}}{A^{2}} \Delta A\right|
$$

Dengan $\Delta A$ ditentukan dari grafik yang dirumuskan dalam bentuk:

$$
\Delta A=\left|\frac{A_{2}-A_{1}}{2}\right|
$$

$A_{1}$ dan $A_{2}$ sebagai gradien garis yang dibuat dengan mempertimbangkan ralat yang dimiliki oleh garis vertikal pada grafik $h T^{2} \quad V s \quad h^{2}$. Ralat $h T^{2}$ diperoleh dengan menggunakan rumus perambatan ralat seperti dilakukan di atas. Dimana dalam perhitungan ralat tersebut adalah sebesar $\pm 0,1$. Yang terakhir $B$ ditentukan dari setengah selisih dari harga mutlak dua titik potong garis yang memiliki gradien masing-masing $A_{l}$ dan $A_{2}$.

Hasil pengukuran dan perhitungan dengan analisa metode I dinyatakan dalam Tabel 1.

Tabel 1. Hasil Pengukuran dan Perhitungan dengan Analisa Metode I

\begin{tabular}{clllll}
\hline No. & $M\left(10^{-3} \mathrm{~kg}\right)$ & $A\left(\mathrm{~s}^{2} / \mathrm{m}\right)$ & $G\left(\mathrm{~m} / \mathrm{s}^{2}\right)$ & $\begin{array}{l}B\left(10^{-2}\right. \\
\left.\mathrm{m} \cdot \mathrm{s}^{2}\right)\end{array}$ & $I\left(10^{4} \mathrm{~m}^{2} . \mathrm{kg}\right)$ \\
\hline 1 & $67,50 \pm 0,05$ & $4,00 \pm 0,20$ & $9,60 \pm 0,40$ & $3,60 \pm 0,10$ & $6,00 \pm 0,20$ \\
2 & $87,40 \pm 0,05$ & $4,00 \pm 0,20$ & $9,80 \pm 0,50$ & $3,80 \pm 0,50$ & $8,00 \pm 0,50$ \\
3 & $117,40 \pm 0,05$ & $4,00 \pm 0,20$ & $9,70 \pm 0,20$ & $3,70 \pm 0,10$ & $10,80 \pm 0,30$ \\
4 & $137,30 \pm 0,05$ & $4,00 \pm 0,20$ & $9,80 \pm 0,40$ & $4,80 \pm 0,20$ & $16,40 \pm 0,80$ \\
\hline
\end{tabular}


2. Menentukan $I_{o}$ dengan Metode II

Ralat $\Delta I_{o}$ dengan teori perambatan ralat dengan $\Delta m$ dan $\Delta g$ telah diperoleh dari perhitungan pada metode I. Sedang $\Delta T$ ditentukan dari grafik $T^{2} v s x$.
Pemecahan mencari $T_{\min }$ dilakukan dengan melihat secara langsung titik terendah yang dihasilkan oleh grafik tersebut. Hasil perhitungan dengan metode II yang dinyatakan dalam Tabel 2.

Tabel 2. Hasil Pengukuran dan Perhitungan dengan Analisa Metode II

\begin{tabular}{crrrr}
\hline No. & \multicolumn{1}{c}{$m\left(10^{-3} \mathrm{~kg}\right)$} & \multicolumn{1}{c}{$T_{\min }(\mathrm{s})$} & \multicolumn{1}{c}{$I_{o}\left(10^{-4} \mathrm{~m}^{2} \mathrm{~kg}\right)$} \\
\hline 1 & 87,40 & $\pm 0,05$ & $0,7670 \pm 0,002$ & $8,10 \pm 0,40$ \\
2 & $117,40 \pm 0,05$ & $0,873 \quad \pm 0,01$ & $10,50 \pm 0,40$ \\
3 & $137,30 \pm 0,05$ & $0,932 \pm 0,004$ & $16,10 \pm 0,60$ \\
\hline
\end{tabular}

Untuk percobaan dengan $m=$ $(67,50 \pm 0,05) \quad 10^{-3} \mathrm{~kg}$, tidak bisa ditentukan harga $I_{o}$ karena ketidak jelasan $T_{\min }$ yang bisa ditentukan dalam grafik yang dihasilkan dalam percobaan ini.

\section{Simpulan dan Saran}

Hasil penelitian ini disimpulkan bahwa:

1. Alat ini dapat bekerja berdasarkan rancangan percobaan yang direncanakan.

2. Dalam menentukan momen kelembaman $(I)$ dapat dilakukan dengan dua metode.

3. Dari grafik $h T^{2}$ vs $h^{2}$ metode I dapat ditentukan momen kelembaman dari gradien garis yang dibuat dan diperoleh nilai momen kelembaman untuk metode I sebesar: $6,00 \pm 0,20\left(10^{-4} \mathrm{~m}^{2}\right.$. $\mathrm{kg}), 8,00 \pm 0,50\left(10^{-4} \mathrm{~m}^{2} . \mathrm{kg}\right), 10,80 \pm$ $0,30\left(10^{-4} \mathrm{~m}^{2} . \mathrm{kg}\right)$ dan $16,40 \pm 0,80$ $\left(10^{-4} \mathrm{~m}^{2} . \mathrm{kg}\right)$.

4. Dari grafik $h T^{2} V s \quad x$ metode II dapat ditentukan momen kelembaman dari gradien garis yang dibuat dan diperoleh nilai momen kelembaman untuk metode II sebesar: $8,10 \pm 0,40\left(10^{4} \mathrm{~m}^{2} . \mathrm{kg}\right), 10,5$

$$
\begin{aligned}
& \pm 0,40\left(10^{-4} \mathrm{~m}^{2} \cdot \mathrm{kg}\right), \quad \text { dan } 16,10 \pm 0,60 \\
& \left(10^{-4} \mathrm{~m}^{2} \cdot \mathrm{kg}\right) .
\end{aligned}
$$

\section{Daftar Pustaka}

Armitage E., 1982. Practical Physics in SI. London: Jhon Murray, Publishers Ltd 50 Albemarle Street

Giancoli, Douglas C. 2001. Fisika Jilid I (Edisi ke -5). (Pentrjemah: Yuhilza Hanun). Jakarta: Erlangga.

Khanafiyah, S. 2012. http://journal. unnes.ac.id/nju/index.php/JPFI/articl e/ download/1000/918 (23 Oktober 2013).

Resnick, Robert \& Halliday, David. 1978. Physics, $3^{\text {ed. }}$. Canada: John Willey.

Sarojo, Ganijati Aby.1978. Mekanika, Teori dan Soal. Jakarta: Jurusan Fisika FIPIA Universitas Indonesia.

Sutrisno. 1997. Fisika Dasar Seri: Mekanika. Bandung: Penerbit ITB

Surya Yohannes.2012. www, yohannessurya.com/download/penulis/AsyikF isika 08.pdf (diakses tanggal 14 november 2013)

Soetarmo. 1985. Fisika. Surakarta: Widya Duta.

Soejoto dan Euis Sustini, 1993. Petunjuk Praktikum Fisika Dasar. Jakarta: Depdikbud, Dirjen Dikti Proyek Pembinaan TKPT. 
Penentuan Momen Inersia Benda Tegar 42 